\title{
Thalidomide Treatment for Immunoglobulin D Multiple Myeloma in a Patient on Chronic Hemodialysis
}

\author{
Tatsuyuki HaYASHI, Izumi YamaguchI, Hiroki SAITOH, Masao TAKAGI, \\ Yasunobu NONAKA and Takeo NOMURA
}

\begin{abstract}
A 64-year-old Japanese man suffering from IgD $\lambda$ myeloma and renal failure requiring chronic hemodialysis was treated with thalidomide. Serum IgD concentration was $4,050 \mathrm{mg} / \mathrm{dl}$ and myeloma cells constituted 95.6\% of nucleated cells in bone marrow at the start of treatment. These parameters improved markedly to $1,590 \mathrm{mg} / \mathrm{dl}$ and $22.0 \%$, respectively, in the 4 months immediately prior to his death due to pneumonia. Thalidomide caused peripheral neuropathy and constipation at a dose of $100 \mathrm{mg}$ daily in the first week of treatment, but adverse effects resolved upon dose reduction. Thalidomide represents a valid therapeutic option for some myeloma patients receiving hemodialysis.

(Internal Medicine 42: 605-608, 2003)
\end{abstract}

Key words: IgD myeloma, renal failure, hemodialysis, thalidomide, optional treatment, adverse effect

\section{Introduction}

Immunoglobulin (Ig) D multiple myeloma is rare, comprising only $2 \%$ of all myelomas $(1,2)$. The condition typically develops in male patients, is often accompanied by hepatosplenomegaly, lymphadenopathy, extraosseous lesions, $\lambda$-type monoclonal component, renal failure and hypercalcemia, and displays a poor prognosis (1-3).

Thalidomide was initially used as a sedative and hypnotic in the late 1950s, but was found to cause birth defects such as phocomelia when taken during the first trimester of pregnancy, and was withdrawn from the global market in 1961 (4). Thalidomide is currently available in Europe and the United States, but sale of this drug has not been approved in Japan. In recent years, thalidomide has re-entered the lime- light as a therapeutic agent against myelomas refractory to chemotherapy (5-7).

We describe herein a patient with IgD myeloma and renal failure requiring chronic hemodialysis who responded to thalidomide treatment.

For editorial comment, see p 550.

\section{Case Report}

A 64-year-old Japanese man was diagnosed with $\operatorname{IgD} \lambda$ type myeloma with Bence Jones proteinuria in April 2001. He was $156 \mathrm{~cm}$ tall and weighed $60.5 \mathrm{~kg}$. Laboratory examinations demonstrated acute renal failure with elevated serum $\beta_{2}$-microglobulin levels of $21.6 \mathrm{mg} / \mathrm{dl}$ and hypercalcemia. Blood counts revealed anemia and leukocytosis, and bone marrow aspiration identified diffuse infiltration of myeloma cells (Table 1). Extraosseous lesions, lymphadenopathy and hepatosplenomegaly were not detected. He had diabetes mellitus and a duodenal ulcer.

After six courses of combination chemotherapy comprising melphalan, vincristine and prednisolone, and occasional bisphosphonate (pamidronate disodium) injections, serum IgD dropped to $2,060 \mathrm{mg} / \mathrm{dl}$ (Fig. 1) and hypercalcemia disappeared in October 2001. However, since anemia progressed and serum creatinine reached $8.7 \mathrm{mg} / \mathrm{dl}$, chronic hemodialysis was performed twice a week with erythropoietin injections and occasional blood transfusions.

In January 2002, serum IgD again increased (Fig. 1) and marked infiltration of myeloma cells into the marrow was observed (Table 1). The patient and his wife then agreed to try thalidomide treatment against relapsed myeloma. Thalidomide treatment was administered after obtaining written informed consent from both individuals and approval from the Human Investigation Committee of our hospital under the protocols of the Helsinki Declaration. Oral thalido-

From the Division of Internal Medicine, Tokyo Metropolitan Police Hospital, Tokyo

Received for publication October 21, 2002; Accepted for publication February 7, 2003

Reprint requests should be addressed to Dr. Tatsuyuki Hayashi, the Division of Internal Medicine, Tokyo Metropolitan Police Hospital, 10-41 Fujimi 2chome, Chiyoda-ku, Tokyo 102-8161 
HAYASHI et al

Table 1. Laboratory Findings

\begin{tabular}{|c|c|c|c|}
\hline & $\begin{array}{c}\text { At diagnosis } \\
\text { (Apr. 17, 2001) }\end{array}$ & $\begin{array}{l}\text { Start of thalidomide } \\
\quad(\operatorname{Jan} .29,2002)\end{array}$ & $\begin{array}{c}\text { Follow-up } \\
\text { (May 29, 2002) }\end{array}$ \\
\hline \multicolumn{4}{|l|}{ Blood count } \\
\hline White blood cells $\left(\times 10^{9} / l\right)$ & 10.7 & 4.3 & 2.1 \\
\hline Neutrophils (\%) & 52.5 & 62.0 & 55.0 \\
\hline Basophils (\%) & 0 & 0.5 & 0.5 \\
\hline Eosinophils (\%) & 1.5 & 0 & 0.2 \\
\hline Monocytes (\%) & 10.0 & 7.0 & 5.4 \\
\hline Lymphocytes (\%) & 31.0 & 30.0 & 38.9 \\
\hline Hemoglobin (g/dl) & 7.7 & $10.5^{*}$ & $10.2 *$ \\
\hline Platelets $\left(\times 10^{9} / l\right)$ & 194 & 144 & 33 \\
\hline \multicolumn{4}{|l|}{ Serum immunoglobulins } \\
\hline $\operatorname{IgG}(\mathrm{mg} / \mathrm{dl})$ & 722 & 519 & 412 \\
\hline $\operatorname{IgA}(\mathrm{mg} / \mathrm{dl})$ & 25 & 10 & 8 \\
\hline $\operatorname{IgM}(\mathrm{mg} / \mathrm{dl})$ & 22 & 11 & 15 \\
\hline $\operatorname{IgD}(\mathrm{mg} / \mathrm{dl})$ & 4,670 & 4,050 & 1,590 \\
\hline $\operatorname{IgE}(\mathrm{IU} / \mathrm{ml})(\mathrm{RIST})$ & 12 & Not tested & Not tested \\
\hline \multicolumn{4}{|l|}{ Blood chemistry } \\
\hline Urea nitrogen $(\mathrm{mg} / \mathrm{dl})$ & 62.8 & 21.0 & 40.2 \\
\hline Creatinine (mg/dl) & 6.4 & 6.1 & 6.9 \\
\hline Serum calcium (mg/dl) & 11.5 & 10.0 & 11.2 \\
\hline \multicolumn{4}{|l|}{ Bone marrow } \\
\hline Myeloma cells (\%) & 94.4 & 95.6 & 22.0 \\
\hline
\end{tabular}

mide tablets were imported from Penn Pharmaceuticals Co. Ltd. (London, UK) with the permission of the Japanese Ministry of Health, Welfare and Labour.

In January 2002, administration of thalidomide was initiated at $100 \mathrm{mg}$ once a day. The patient was emaciated (weight, $43 \mathrm{~kg}$ ) by this time. However, the patient complained of generalized sensory disturbance and numbness (grade 2 according to World Health Organization classifications) and constipation (grade 1) in the first week of therapy. Dosage was therefore reduced to $100 \mathrm{mg}$ every 3 days and the adverse effects disappeared. Once on chronic hemodialysis, the patient tolerated thalidomide well at a dose of $100 \mathrm{mg}$ every other day. By the end of May 2002, serum IgD was decreasing (Fig. 1) and myeloma cells had diminished in the marrow (Table 1), although hematopoiesis did not recover. The patient died of pneumonia in early June 2002.

\section{Discussion}

The prognosis of our patient was considered very poor at the diagnosis of IgD myeloma. In IgD myeloma patients, median survival time is reportedly 9-21 months (1-3). Furthermore, reference to a multivariate analysis of 165 Japanese IgD myeloma patients indicated that our patient, with leukocytosis and $\lambda$ type paraproteinemia at diagnosis, belonged to a high risk group with a median survival time of only 8 months (3). In addition, our patient displayed irreversible renal dysfunction that was resistant to chemotherapy and required chronic hemodialysis. Mean survival time of myeloma patients who develop acute renal failure that is refractory to chemotherapy is reportedly 7.8 months, which is significantly shorter than that of myeloma patients with reversible renal failure (8). Furthermore, in one series of myeloma patients, the survival rate at 1 year was $45 \%$ after initiation of chronic dialysis (9).

The present patient initially displayed a favorable response to chemotherapy, but relapse occurred after the development of renal failure requiring chronic hemodialysis. Administration of aggressive chemotherapy was difficult due to poor general condition and renal failure. Thalidomide treatment was therefore considered. Oral thalidomide has been administered for myeloma refractory to chemotherapy with a reported response rate of $32-43 \%$ (5-7), and eventfree survival and overall survival after 1 year of follow-up of $22 \%$ and $58 \%$, respectively (5). The antitumor activity of thalidomide is thought to involve inhibition of angiogenesis, alteration of the expression of adhesion molecules, suppression of the production of tumor necrosis factor $\alpha$, increased production of interleukin 10, enhancement of cell-mediated immunity, and complex effects by cytokines (5).

When our patient and his wife requested thalidomide treatment against the relapsed myeloma, we faced the prob- 


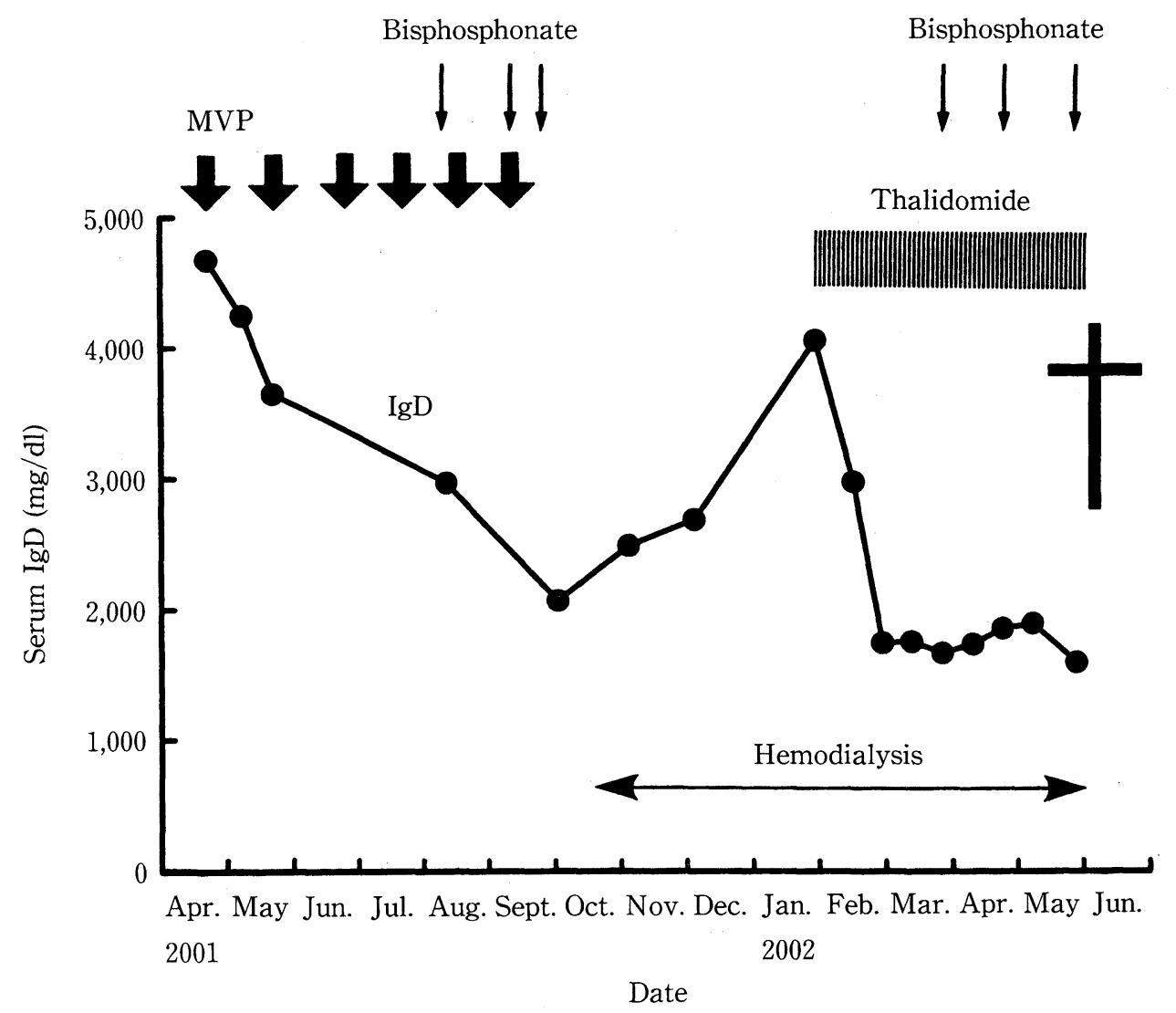

Figure 1. Serum IgD M-protein levels in the patient. Bisphosphonate: pamidronate disodium $30 \mathrm{mg} /$ day, MVP: melphalan $8 \mathrm{mg} / \mathrm{m}^{2}$ for 4 days, vincristine $1.5 \mathrm{mg} / \mathrm{m}^{2}$ for 1 day, and prednisolone $30 \mathrm{mg} / \mathrm{m}^{2}$ for 4 days.

lem of the lack of previous reports of thalidomide treatment against myeloma in chronic hemodialysis. Moreover, serum concentrations of thalidomide could not be measured at our laboratory, or at any other commercial laboratories in Japan, complicating the determination of a maintenance dose. The dosage of thalidomide against myeloma has ranged from 100 $\mathrm{mg}$ to $800 \mathrm{mg}$ daily (5-7). Thalidomide is predominantly excreted by nonrenal routes, and is detected in plasma up to 24 hours after a single oral dose of $200 \mathrm{mg}$ in healthy volunteers (4). A daily dose of $100 \mathrm{mg}$ of thalidomide is reportedly effective for uremic pruritus without any adverse effects in uremic patients requiring hemodialysis (10). In addition, our patient was of small stature, and was also emaciated. An initial dose of thalidomide of $100 \mathrm{mg}$ daily was therefore selected for our patient.

The patient then complained of peripheral neuropathy and constipation. Constipation, weakness or fatigue, and somnolence are the principal adverse effects of thalidomide treatment, occurring in one-third or more of myeloma patients $(5$, 6). Peripheral nerve palsy caused by thalidomide is less common among myeloma patients (5-7), and is more often observed among patients with dermatologic conditions, suggesting a dose-dependent effect (4). Adverse effects in the present case improved upon dose reduction of thalidomide from $100 \mathrm{mg}$ daily to $100 \mathrm{mg}$ on alternative days.

Over 50\% reduction in $\mathrm{IgD}$ was attained within 2 months in our patient, not by chemotherapy but by thalidomide treatment, and notably, using a smaller dose than previously reported (5-7). One reason for this is presumably the short stature and emaciation of our patient. However, some uncertainty remains as to whether lower doses of thalidomide may be effective in myeloma patients receiving dialysis. In another study, dialysis patients with myeloma who attained a more than 50\% reduction in paraprotein in response to chemotherapy survived significantly longer than those who did not (9). Unfortunately, the present patient died of pneumonia, and the survival time from diagnosis of myeloma was 14 months. Reductions of IgD in serum and plasmacytosis in marrow indicated that our patient was a responder to thalidomide treatment (5-7) before the fatal lung infection. The duration of partial response in our patient was 4 months, which was shorter than that of a previous report (6).

Conversely, the present patient demonstrated cytopenia, hypercalcemia and suppression of serum immunoglobulins, suggesting the progression of myeloma just before death. The existence of extraosseous lesions could not be excluded, 


\section{HAYASHI et al}

as general examinations were not performed on our patient at that time, and extraosseous lesions do not seem to respond to thalidomide, even if reduction of serum paraprotein is achieved (6). Worthy of note is the fact that cytopenia is one of the known adverse effects of thalidomide (5), and some patients develop pneumonia during thalidomide treatment (6). The possible contribution of thalidomide to the death of our patient therefore could not be excluded, although treatment-related mortality was not observed in another report (7).

In conclusion, thalidomide treatment is recommended for patients with IgD myeloma, in addition to those with other types of myelomas that are refractory to or display contraindications for chemotherapy. Thalidomide can be administered to myeloma patients on chronic hemodialysis, although careful consideration of the dose and potential adverse effects must be made.

\section{References}

1) Jancelewicz Z, Takatsuki K, Sugai S, Pruzanski W. IgD multiple myeloma: Review of 133 cases. Arch Intern Med 135: 87-93, 1975.

2) Bladé J, Lust JA, Kyle RA. Immunoglobulin D multiple myeloma:
Presenting features, response to therapy, and survival in a series of 53 cases. J Clin Oncol 12: 2398-2404, 1994.

3) Shimamoto Y. IgD myeloma: Clinical characteristics and a new staging system based on analysis of Japanese patients. Cancer Detect Prev 19: 426-435, 1995.

4) Tseng S, Pak G, Washenik K, Pomeranz MK, Shupack JL. Rediscovering thalidomide: A review of its mechanism of action, side effects, and potential uses. J Am Acad Dermatol 35: 969-979, 1996.

5) Singhal S, Mehta J, Desikan R, et al. Antitumor activity of thalidomide in refractory multiple myeloma. N Engl J Med 341: 1565-1571, 1999.

6) Juliusson G, Celsing F, Turesson I, Lenhoff S, Adriansson M, Malm C. Frequent good partial remissions from thalidomide including best response ever in patients with advanced refractory and relapsed myeloma. Br J Haematol 109: 89-96, 2000.

7) Barlogie B, Zangari M, Spencer $T$, et al. Thalidomide in the management of multiple myeloma. Semin Hematol 38: 250-259, 2001.

8) Pasquali S, Casanova S, Zucchelli A, Zucchelli P. Long-term survival patients with acute and severe renal failure due to multiple myeloma. Clin Nephrol 34: 247-254, 1990.

9) Iggo N, Palmer ABD, Severn A, et al. Chronic dialysis in patients with multiple myeloma and renal failure: A worthwhile treatment. Quart J Med 73: 903-910, 1989.

10) Silva SRB, Viana PCF, Lugon NV, Hoette M, Ruzany F, Lugon JR. Thalidomide for the treatment of uremic pruritus: A crossover randomized double-blind trial. Nephron 67: 270-273, 1994. 